\title{
GUY VELOSO: UMA TRAVESSIA COM OS IRMÃOS DAS ALMAS
}

\section{Marisa Mokarzel}

\section{Resumo}

Este artigo analisa fotografias de Guy Veloso pertencentes à série Penitentes: dos Ritos de Sangue à Fascinação do Fim do Mundo que teve início em 2002. Doze dessas imagens foram expostas na 29a Bienal de São Paulo, realizada em 2010. No processo analítico estão presentes questões específicas da estética fotográfica e concernentes à abordagem sociopolítica. A base teórica foi desenvolvida a partir de Andre Rouillé e Euclides da Cunha.

\section{Palavras-chave:}

Fotografia; Guy Veloso; Religiosidade; Penitentes.

\section{Abstract:}

This article looks at photographs of Guy Veloso belonging to Penitents series: Blood Rites of the fascination of the End of the World which started in 2002. Twelve of these images were exhibited at the 29th São Paulo Biennial, held in 2010. In the analytical process issues are present specific photographic aesthetics and concerning the sociopolitical approach. The theoretical basis was developed from Andre Rouille and Euclides da Cunha.

\section{Keywords:}

Photography; Guy Veloso; Religiosity; Penitents. 
Em que momento o tema religioso abriga-se na lente do fotógrafo e juntos percorrem estradas, ruelas distantes em noites de mistério e de indecifráveis sentimentos? O tema talvez provenha da infância, das rezas corriqueiras feitas antes de dormir, que podem ou não ter existido e se instalado na curiosidade de um ritual incorporado ao hábito noturno, cumprido no tempo que antecede ao sono e aos sonhos. O certo é que em 1993 aos 23 anos, recém-formado em direito, Guy Veloso parte rumo à Espanha com o desejo de caminhar até Santiago de Compostela. Na rota medieval, seguida por seus passos, leva a câmera fotográfica e pela trilha religiosa vai registrando povoados, singelos moradores, cruzes e estradas nas quais o céu encontra-se com o topo dos antigos prédios, redesenhando as imagens captadas por olhos que iam além do documento, dotando o ato fotográfico de uma sensível e perspicaz interpretação do mundo.

Naqueles instantes de Espanha, nascia a opção por uma trajetória que o deixaria cada vez mais distante do campo do Direito e mais próximo da fotografia. No estranho céu invadido por fantasmagóricas nuvens já se antevê a quase pintura, as futuras imagens impregnadas de mistérios, realizadas em outro cenário, desta vez no Brasil. A câmera analógica volta-se agora para as comunidades secretas, muitas vezes encapuzadas que encobrem as faces sofridas, perdidas em lugarejos nos quais os pequenos grupos laicos, envoltos em rituais religiosos, saem ao som das matracas, em caminhadas noturnas a cantar e rezar pelas almas perdidas. Perdidas de quê? De pecados que carregaram em vida? De dores que se transformaram em lamentos e foram levados para além-túmulo? O que mais dilacera: a dor vivida nas terras esquecidas ou o eterno golpe jamais cicatrizado com a morte?

Dos ritos advêm as narrativas imagéticas retiradas dos penitentes, mas transformadas em ficção pela cor, pela luz, pelo enquadramento ou pela força interpretativa do fotógrafo que consegue estabelecer um processo comunicativo com aquele que vê as imagens e realiza nova interpretação, segundo suas próprias vivências e a estética proposta por Veloso.
O projeto Penitentes: dos Ritos de Sangue à Fascinação do Fim do Mundo tem início em 2002, são dez anos de um trabalho minucioso que gerou infinitas imagens conseguidas nas inúmeras locomoções de Guy Veloso por todas as regiões brasileiras. O mapeamento e a aproximação do fotógrafo com os grupos de penitentes - que não representam uma uníssona voz, mas diferentes formas de manifestação laica religiosa - exigem paciência e a constituição de uma rede de amizade que envolve relações de afetividade, respeito e confiança.

A lenta e gradativa descoberta de cada grupo de penitentes compôs uma série de arquivos perpassados por questões religiosas, históricas, antropológicas e sociológicas. Todavia, nenhuma dessas questões, presentes na imagem, se sobrepõem às questões específicas da fotografia e da arte. Por mais que Guy Veloso se interesse em recoIher narrativas, cantos, paramentos e instrumentos utilizados pelos Irmãos das Almas', nenhuma dessas atitudes se sobrepõe ao olhar que dota as imagens de elementos que concernem à própria fotografia ou diz respeito à arte e à estética predominante que as distinguem de outras de caráter apenas documental.

Pode-se perguntar como em Guy Veloso uma fotografia produtora de inventários que destacam fatos de um Brasil muitas vezes composto por descaso, dores, fome e miséria pode, sem esquecer esses substantivos, transformar-se em uma fotografia instigante, impulsionada pela cor e luz, aproximando-se da pintura ${ }^{2}$ ? Sabe-se que "enquanto o pintor trabalha por adição de matéria sobre a tela, enquanto, pincelada por pincelada, ele constrói conjuntos, o fotógrafo trabalha por subtração, desmantela a continuidade do visível de onde extrai suas imagens"3. Veloso utiliza sem dúvida o recurso da subtração, desmontando a continuidade da cena, propondo o seu recorte para transformar o "real em um real fotográfico"4. Ao transpor o que testemunha para um real específico da linguagem da fotografia, o fotógrafo aproxima-se mais do processo criativo do que do documental. Ao pontuar a cor e combiná-la com a luz, elege esses dois elementos como escolhas fundamentais à estética que se impõe e termina por atribuir à imagem o valor de arte. 
Fotografia e arte imbricadas em uma longa pesquisa revelam o eixo religioso de um tema que traz à tona as contradições de um país que muitas vezes conduz sua história por subterrâneos canais, esquecida antes de se fazer conhecer. Guy Veloso nasceu em Belém do Pará, cidade situada em plena Amazônia, região que propiciou inúmeras lendas, motivou imaginários na formação de imagens ilusórias, às vezes mais próximas da aventura do que da própria realidade. Entre os muitos viajantes e as construções de verdades que apontavam "paraísos perdidos" destaca-se uma visão talvez mais concreta, apresentada por Euclides da Cunha que percebeu a Amazônia da época da borracha como "uma terra sem história"5. Acreditava que esta região encontrava-se sequestrada do resto do país e que a situação precária e instável do seringueiro devia-se, além da riqueza concentrada nas mãos de poucos, ao fato da distância na qual a Amazônia se situava em relação aos estados brasileiros de maior poder econômico.

O mundo contemporâneo demarcado por diluídas fronteiras e processos globalizantes promove contatos entre localidades geograficamente Iongínquas e por esta razão parece não mais permitir o isolamento, uma vez que encurta distâncias e tempos em função das novas tecnologias, em função de novas cartografias. Contudo, o Brasil caracteriza-se por contrastantes realidades em que a mais alta tecnologia convive com técnicas rudimentares, enquanto a riqueza se contrapõe a uma miséria desconcertante. A maioria dos penitentes localiza-se no espaço restrito daqueles que, por viverem em estado constante de penúria, aparentemente abdicam do progresso, destituindo-se da riqueza, por acreditarem que a pobreza é o bem que os tornará mais próximo de Deus. Crença no que se constitui um paliativo para o insuportável da dor? Ou imposições de um estado de carestia decorrente da falta de uma política econômica e social mais justa, menos desigual?

Hoje como ontem, as políticas públicas muitas vezes não inserem em seus projetos medidas práticas que possam sanar as dificuldades econômicas e sociais - desde sempre apresentadas por um país de dimensões continentais. Em 1904, quando se formou a Comissão Mista Brasileiro-
Peruana de Reconhecimento do Alto Purus. O objetivo era demarcar a fronteira entre o Brasil e o Peru e estas delimitações estariam relacionadas com o domínio de uma situação econômica favorável, possibilitada pela extração da borracha. No entanto, aqueles que ajudavam diretamente no processo de extração não só não participavam dos lucros como também trabalhavam para escravizar-se. Esta era a opinião de Euclides da Cunha que foi designado pelo Barão do Rio Branco para chefiar a expedição, fazer um levantamento cartográfico, observar a nascente do rio. 0 encontro com a Amazônia foi para o escritor mais um motivo para desenvolver a sua análise e pensamento crítico sobre o Brasil, terra constituída por uma geografia de isolamento, construtora de histórias sofridas.

A maioria dos que trabalhavam nos seringais eram nordestinos. A escravidão por dívida delineava-se nessa geografia humana formada entre Norte e Nordeste, regiões nas quais os penitentes, com suas rezas e cânticos, tornaram-se mais presentes. Floresta, deserto ou sertão? Onde situar a ideia messiânica de levar o conforto de Deus aos oprimidos, aos Irmãos das Almas? Seringueiro ou sertanejo? Qual aquele que guiará as orações e cobrirá seu rosto para que o secreto se instale e ajude na remissão dos pecados? Sem o rosto coberto, Antônio Conselheiro se fez penitente e peregrino, incorporando o messias errante, identificado como o louco inimigo antirrepublicano. Sem navegar pelo rio Purus, fez suas preces, pregou seus sermões não em águas do Norte, mas em terras nordestinas. Em pleno sertão da Bahia tornou-se líder do arraial de Canudos.

Antes da expedição que o levou até a Amazônia, Euclides da Cunha, ainda no final do século XIX, testemunhou a luta acirrada e desigual entre o grupo de Conselheiro e o exército brasileiro. Em seu livro Os Sertões: campanha de Canudos, o autor narra o final da Guerra, dá-nos a triste dimensão da inacreditável resistência de miseráveis beatos diante da ação bélica do exército.

Canudos não se rendeu. Exemplo único em toda a História, resistiu até ao esgotamento completo. Expugnado palmo a palmo, na precisão integral do termo, caiu no dia 5, ao entardecer, quando caíram os seus últimos defensores, que todos morreram. 
Eram quatro apenas: um velho, dois homens feitos e uma criança, na frente dos quais rugiam raivosamente cinco mil soldados. ${ }^{6}$

Naquele instante, o "Fim do Mundo" era aqui. Em terras brasileiras, os ritos de sangue começaram ou seguiram em seitas sem se saber se sua origem datava das perseguições aos cristãos. A cena árida como o próprio sertão, deixava expostos não os vestígios que remontam às catacumbas, ao início da Idade Média, mas a terra seca que em 1897 mimetizou-se ao corpo esquálido de Antônio Conselheiro. "Fotografaram-no depois, E lavrou-se uma ata rigorosa firmando sua identidade: importava que o país se convencesse bem de que estava afinal extinto aquele terribilíssimo antagonista"7. O real aproximou-se do absurdo e ambíguo situou-se no limiar da ficção, na construção de uma história cuja imaginação do escritor, artista ou fotógrafo já não podia alcançar.

Guy Veloso visita os herdeiros de Conselheiro. Contudo, o clima de absurdo, quase surreal, presente em suas fotos, não parte do pesadelo que se configurou no século XIX, no sertão da Bahia. Mais de cem anos depois, redesenha-se outra realidade, menos bélica, mas não menos sofrida. Muitos protagonistas são vítimas da seca, fanáticos em seus princípios, seguem a rigidez das normas que formatam suas vidas em peregrinações e devoções. Responsáveis por amenizar o pecado do mundo, rezam pelas almas, procuram ajudar o próximo, serem ajudados. A topografia de $\mathrm{Ca}^{-}$ nudos "modelava-se ante a imaginação daquelas gentes simples como o primeiro degrau amplíssimo e alto, para os céus..." ${ }^{8}$ Em pleno século XXI, errantes continuam partindo em romaria para galgar os degraus que os farão alcançar os céus.

Nas 12 imagens selecionadas para participar da 29a Bienal de São Paulo, realizada em 2010 com curadoria geral de Agnaldo Farias e Moacir dos Anjos, o tema afinava-se com essa errância religiosa manifesta em algumas comunidades brasileiras. A temática da bienal concentrava-se na ideia de que arte e política são inseparáveis, uma vez que o mundo norteia-se por conflitos que geram disputas de poder e essas disputas refletem-se na vida, na arte. A potencialidade simbólica e poética das fotografias de Guy Veloso coadunava-se com o pensamento curatorial, trazendo ao mesmo tempo a força de uma manifestação laica religiosa e a interpretação muito particular desse universo de penitentes permeado por questões sociais, históricas e políticas.

As fotografias da Bienal, que primeiramente eram 16, também recebeu o apoio curatorial de RoseIy Nakagawa, que uniu o conjunto de fotos com a presença desses espíritos sofredores, guiados por preceitos rígidos que geram ações impregnadas de mistério, acompanhadas por corpos cobertos por indumentárias muitas vezes criadas com mantos ou lençóis. Das fotos destinadas à Bienal, duas foram realizadas em 2002 e 2008 e as demais em 2005. As cenas impressionam pela cor, pela luminosidade, pela paisagem quase ficcional que se integra às estranhas personagens.

Não é o acaso que se inscreve na proximidade com a questão surreal, mas a imagem em si que subverte a realidade e reescreve o fato, trazendo- o para o campo fotográfico. De onde vem o azul noturno da silhueta sob o lençol que se movimenta em um terreno marrom quase púrpura que conduz ao céu? De onde vem essa personagem perdida em rezas ou envolta em dúvidas que foi flagrada pelo fotógrafo? De onde surgiu a figura branca pousada no topo do muro, escondida em máscara, destacada no amarelo que ilumina o prédio ao fundo? São penitentes de Senhora da Glória e de Laranjeiras, em Sergipe, são figuras que se desprenderam de algum lugar e fantasmagóricas habitam ambíguas narrativas que atiçam imaginários e promovem estéticas que reinventam luz e planos.

Veloso revela que sempre gostou do tema da religiosidade e que estudar questões metafísicas, esotéricas é de sua predileção. 0 domínio da técni$c a$, a concentração no ato fotográfico traz à tona o fragmento do real que se virtualiza. O que foi visto ganha uma luminosidade específica que transcende a própria realidade, a pintura em luz segue a vontade do fotógrafo que se sobrepõe à máquina e invade o terreno do sensível, dando novo significado à imagem captada. Sem perder a força da violenta gestualidade do penitente, Guy Veloso faz com que o autoflagelo não se torne explícito 
9. Rouillé, André, Op. Cit., pp. 158-159

\section{Referências}

CUNHA, Euclides Rodrigues Pimenta da. Os Ser-

tões: campanha de Canudos. $27^{a}$ edição. Brasília:

Editora Universidade de Brasília, 1963.

Euclides. Amazônia: um paraíso perdido.

Manaus: Editora Valer, 2011.

ROUILLÉ, André. A fotografia: entre documento e arte contemporânea. São Paulo: Editora Senac São Paulo, 2009, pp. 101-102.

\section{Sobre a autora}

Marisa Mokarzel possui doutorado em Sociologia pela Universidade Federal do Ceará (2005) e mestrado em História da Arte pela Universidade Federal do Rio de Janeiro (1998). Foi pesquisadora do Sistema Integrado de Museus e Memoriais-SIM/SECULT/PA. Foi diretora do Espaço Cultural Casa das Onze Janelas da Secretaria de Cultura do Pará. Exerceu a coordenadoria adjunta do Mestrado em Comunicação, Linguagens e Cultura da Universidade da Amazônia - UNAMA. Professora Titular Pós Stricto Sensu da UNAMA: Mestrado em Comunicação, Linguagens e Cultura; curso de Artes Visuais e Tecnologia da Imagem; e curso de Moda. Tem experiência na área de Artes Visuais, com ênfase em História da Arte, atuando principalmente nos seguintes temas: circuito de arte, exposição e curadoria. 